\title{
Usage of TCRAV and TCRBV gene families in human fetal and adult $T C R$ rearrangements
}

\author{
Frank M. Raaphorst ${ }^{1,2}$, Jeroen van Bergen1, Renée Langlois van den Bergh'2, Maarten van der Keur ${ }^{3}$, \\ Ronald de Krijger ${ }^{4}$, Jan Bruining ${ }^{4}$, Maarten J. D. van Tol${ }^{2}$, Jaak M. Vossen², Peter J. van den Elsen ${ }^{3}$ \\ 1 Department of Immunohematology and Bloodbank, Leiden University Hospital, P. O. Box 9600, 2300 RC Leiden, The Netherlands \\ 2 Department of Pediatrics, Leiden University Hospital, P. O. Box 9600, 2300 RC Leiden, The Netherlands \\ ${ }^{3}$ Department of Cytochemistry and Cytometry, Sylvius Laboratories, Leiden University, Wassenaarseweg 72, 2333 AA Leiden, \\ The Netherlands \\ ${ }^{4}$ Department of Pediatrics, Subdivision of Clinical Genetics, Erasmus University/Sophia Children's Hospital, Dr. Molenwaterplein 60 , \\ 3015 GJ Rotterdam, The Netherlands
}

Received November 30, 1993/Revised version received January 10, 1994

\begin{abstract}
We have investigated fetal and adult T-cell receptor $(T C R) A$ and $B V$-gene repertoires both by fluorescence-activated cell sorter (FACS) analysis with the available $T C R V$ region-specific mAbs and by the polymerase chain reaction (PCR) with $T C R V$ gene family-specific oligonucleotides. Among the low number of $\mathrm{CD}^{+} \mathrm{T}$ cells, most of the TCR $V$ regions tested for could be detected by FACS analysis in liver, bone marrow, and spleen derived from a 14-week-old fetus and two 15-week-old fetuses. Similarly, the PCR analysis showed that the majority of the TCRAV and TCRBV families were expressed in the peripheral organs of the 13-week-old fetus, although an apparent absence of particular TCR $V$ families was found in liver and bone marrow. This was most probably the consequence of the low number of $\mathrm{CD}^{+} \mathrm{T}$ cells in these organs. In 17week-old fetal thymi the level of expression of some $T C R A V$ and TCRBV gene families, in particular those that contain a single member, was lower compared to post-partum thymi and adult peripheral blood mononuclear cells. The combined data of FACS and PCR analysis demonstrate that $T C R V$ genes belonging to the majority of TCR $V$ gene families can be used in TCR $\alpha$ and $\beta$ chain rearrangements during early human fetal life. Our data also suggest that the expression levels of some of the single member $T C R V$ gene families may be influenced by the developmental stage.
\end{abstract}

\section{Introduction}

T-lymphocytes specifically recognize processed peptide antigens, presented by major histocompatibility complex molecules, via the T-cell receptor (TCR; reviewed

Correspondence to: $\mathrm{P}$. J. van den Elsen. in Strominger 1989). TCRs can be divided into two classes: the $\alpha \beta T C R$, expressed on the majority of peripheral $\mathrm{T}$ lymphocytes, and the $\gamma \delta$ TCR (Brenner et al. 1986, 1987; Strominger 1989). Both chains of these heterodimeric TCRs are composed of variable and constant regions. Variable regions are assembled from germ-line encoded variable $(V)$, diversity $(D$; only present in $\beta$ chains), and joining $(J)$ elements through a process called $V(D) J$ recombination (reviewed in Schatz et al. 1992). The currently known human $T C R V$ elements have been grouped into $29 T C R A V$ families and $24 T C R B V$ families; the majority of these contain only a single member (Concannon et al. 1986; Kimura et al. 1987; Wilson et al. 1988; Ferradini et al. 1991; Plaza et al. 1991; Robinson 1991; Roman-Roman et al. 1991).

Cells committed to the T-cell lineage are detectable in human fetal liver as early as the eighth week of gestation, although at this stage of fetal life rearrangement of the TCR genes is undetectable (Asma et al. 1983; Sánchez et al. 1993). From 12 weeks of gestation onwards the bone marrow is the primary site of lymphopoiesis (Asma et al. 1983, 1984; Gale 1987; Abe 1989). The thymus is colonized by (pre) $\mathrm{T}$ cells, generated in the hematopoietic organs at 8 or 9 weeks of gestation, and remains the major site for T-cell differentiation and selection of the TCR repertoire (Asma et al. 1983, 1984; Gale 1987; Haynes et al. 1988; Abe 1989; Sánchez et al. 1993). TCRA and TCRB gene rearrangements have been detected in the human fetal thymus as early as 15 weeks of gestation (Campana et al. 1989) but are likely to be initiated at an earlier stage.

Rearrangement of TCR gene elements is an ordered process. For instance, studies of mouse and human T-cell development (Born et al. 1985; Samelson et al. 1985) and analysis of human CD3- T-cell acute lymphoblastic leukemias (Furley et al. 1986; Van Dongen et al. 1987) have shown that the TCRB and TCRG loci rearrange before the TCRA and TCRD loci. Previously, 
we and others have demonstrated that the employment of the various TCR $V$ gene elements in mouse and human TCR $\delta$ chain rearrangements is under developmental control. Furthermore, the overall usage of $T C R D V$ elements is influenced by post-thymic peripheral modification (Elliot et al. 1988; Ito et al. 1989; Lafaille et al. 1989; Krangel et al. 1990; Van der Stoep et al. 1990). The usage of TCRGV and TCRGJ gene elements was found to be tissue-specific during mouse fetal life (Lafaille et al. 1989). Some of these observations have also been made regarding the usage pattern of TCRAJ elements during mouse development (Roth et al. 1991).

To gain an insight into the generation of the repertoire of $\alpha \beta$ chain TCRs and possible developmental influences on the usage of TCR $V$ gene families during the establishment of the human TCR $A$ and $B$ repertoire, we have investigated the usage of TCRAV and TCRBV families in TCR rearrangements derived from fetal liver, bone marrow, and spleen obtained at $14(n=1)$ and 15 weeks $(n=2)$ of gestation, using fluorescence-activated cell sorter (FACS) analysis. As the number of monoclonal antibodies specific for human $T C R V$-regions is limited and fetal liver and bone marrow contain extremely low numbers of $\mathrm{T}$ cells, we have also determined TCRAV and TCRBV gene family expression in adult peripheral blood mononuclear cells (PBMC), two human post-partum thymi, two human fetal thymi at 17 weeks of gestation, and in human fetal liver, bone marrow, spleen, gut, and cord blood at 13 weeks of gestation, using the polymerase chain reaction (PCR).

\section{Materials and methods}

Human organs. Human fetal tissue was acquired by interruption of pregnancy on nonmedical grounds and used for the experiments after informed consent. The gestational age was determined by measurement of the foot length (Moore 1988). As a consequence of the suction procedure we were unable to locate the thymi of the younger fetuses. The use of this material for research purposes was approved by the Ethical Research Committees of the University Hospitals of Leiden and Rotterdam under strict conditions.

To obtain fetal bone marrow, long bones were flushed with phosphate buffered saline, containing $5 \%$ bovine serum albumin (BSA) and $0.25 \%$ Na-ethylenediaminetetraacetate (EDTA) and the cells were pelleted. Bone marrow of the 11-week-old fetus was not investigated, as lymphopoiesis is marginal at this point of gestation. For PCR analysis, pelleted bone marrow and the other fetal organs were immediately frozen in liquid nitrogen and stored at $-80^{\circ} \mathrm{C}$. For FACS analysis, single-cell suspensions were prepared from liver, bone marrow, and spleen as previously described (Asma et al. 1983, 1984). Mononuclear cells were isolated by Ficoll/ Isopaque density gradient centrifugation. Post-partum thymi were obtained from pediatric patients undergoing cardiac surgery. Adult peripheral blood was obtained by venepuncture from a healthy donor; PBMC were isolated by Ficoll/Isopaque density gradient centrifugation.
Characterization of fetal T cells by immunological staining. TCR V region usage of fetal $T$ cells was analyzed by double staining for CD3 with Leu4-PE (Becton Dickinson, Mountain View, CA) or OKT3-PE (Ortho Diagnostic Systems, Raritan, NJ) combined with $\mathrm{V} \beta 2$ - V $\beta 3$-, V $\beta 8$-, V $\beta 17$-, and V $\beta 19$-specific monoclonal antibodies (mAbs; Immunotech, Marseille, France) and V $\beta 5 \mathrm{a}-$, V $\beta 5 \mathrm{~b}-$, V $\beta 5 c-, V \beta 6-, V \beta 8 b-, V \beta 12-, V \alpha 2-$, and V $\alpha 12$-specific mAbs (T cell Sciences, Cambridge, MA), respectively. After washing the cells, we detected membrane-bound unconjugated $T C R V$ regionspecific $\mathrm{mAbs}$ with the FITC-labelled IgG fraction of goat antisera (Nordic Immunological Laboratories, Tilburg, the Netherlands) against the IgG subclass of the particular mAb.

FACS analysis. Stained cells were analyzed with a FACS (FACStar, Becton Dickinson) equipped with an argon ion laser tuned at $300 \mathrm{~mW}$ of $488 \mathrm{~nm}$ excitation light. The forward light scatter was detected with a photodiode, whereas the orthogonal light scatter and red and green fluorescence emission signals were detected by photomultiplier tubes. The green and red emission were measured with band-pass type interference filters (530/30; type no. 1962774-00, and 585/42; type no. 19-62774-03, Becton Dickinson, respectively). A $560 \mathrm{~nm}$ dichroic mirror (type no. 19-62772-00, Becton Dickinson) was used to separate spectrally the FITC and the PE emission. All signals were recorded as 256 channel histograms and stored into list-mode, using a consort-30 computer program (Becton Dickinson) on an HP-300 computer system (Hewlett Packard). In samples from liver and bone marrow at least 150000 nucleated cells were analyzed because of the low percentages of $\mathrm{CD}^{+}$cells; for the spleen this figure was at least 50000 nucleated cells. The data obtained by using the unconjugated $T C R V$ region-specific mAbs followed by mouse IgG subclass-specific conjugate were corrected for background staining by application of the latter antibody only.

Optimal setting of the lymphocyte (and blast) gate for cell suspensions of the different organs was based on the fluorescence pattern obtained after staining of the cells with a cocktail of mAbs against CD45 (Becton Dickinson), CD33 (Becton Dickinson), and Glycophorin A (Immunotech).

Method validation. As the number of T cells in fetal liver and bone marrow was extremely low, we assessed whether the percentage of $T$ cells expressing the TCRBV3 family as determined by our assay was influenced by the number of $\mathrm{CD}^{3}+\mathrm{T}$ cells in a given sample. We therefore mixed adult PBMC with a CD3- CD10+ pre-B leukemic cell line in several ratios $(100: 0,75: 25,50: 50,25: 75)$. The results demonstrated that, irrespective of the ratio, the percentage of TCRBV3+ $\mathrm{T}$ cells within the $\mathrm{CD} 3^{+}$population remained constant. Therefore, detection of this TCRBV family was not influenced by the number of CD3+ T cells present in the sample (data not shown).

RNA extraction, CDNA synthesis, PCR analysis, and Southem blotting. RNA was extracted with guanidinium salts, using standard laboratory methods (Sambrook et al. 1989) and dissolved into $40 \mu \mathrm{l}$ of DEPC-treated water. Five $\mu \mathrm{g}$ of RNA was used for oligo dT-primed cDNA synthesis, using reverse transcriptase (Riboclone cDNA synthesis system; Promega, Madison, WI). Following phenol extraction, the double-stranded cDNA was dissolved in $100 \mu \mathrm{TE}$. The expression of TCRAV and TCRBV gene families was analyzed, using PCR amplification as previously described by our laboratory (Lambert et al. 1992; Van Eggermond et al. 1993; Hawes et al. 1993; Struyk et al. 1993), with minor modifications. Briefly, $0.5 \mu \mathrm{cDNA}$ was amplified, using $20 \mathrm{pmol} T C R A V$ - and $T C R B V$-specific $5^{\prime}$ sense primers, 20 pmol $3^{\prime}$ antisense TCRAC primer or a TCRBC primer specific for both $T C R B C 1$ and TCRBC2 loci, and 2.5 units Taq DNA polymerase (Boehringer, Mannheim, 

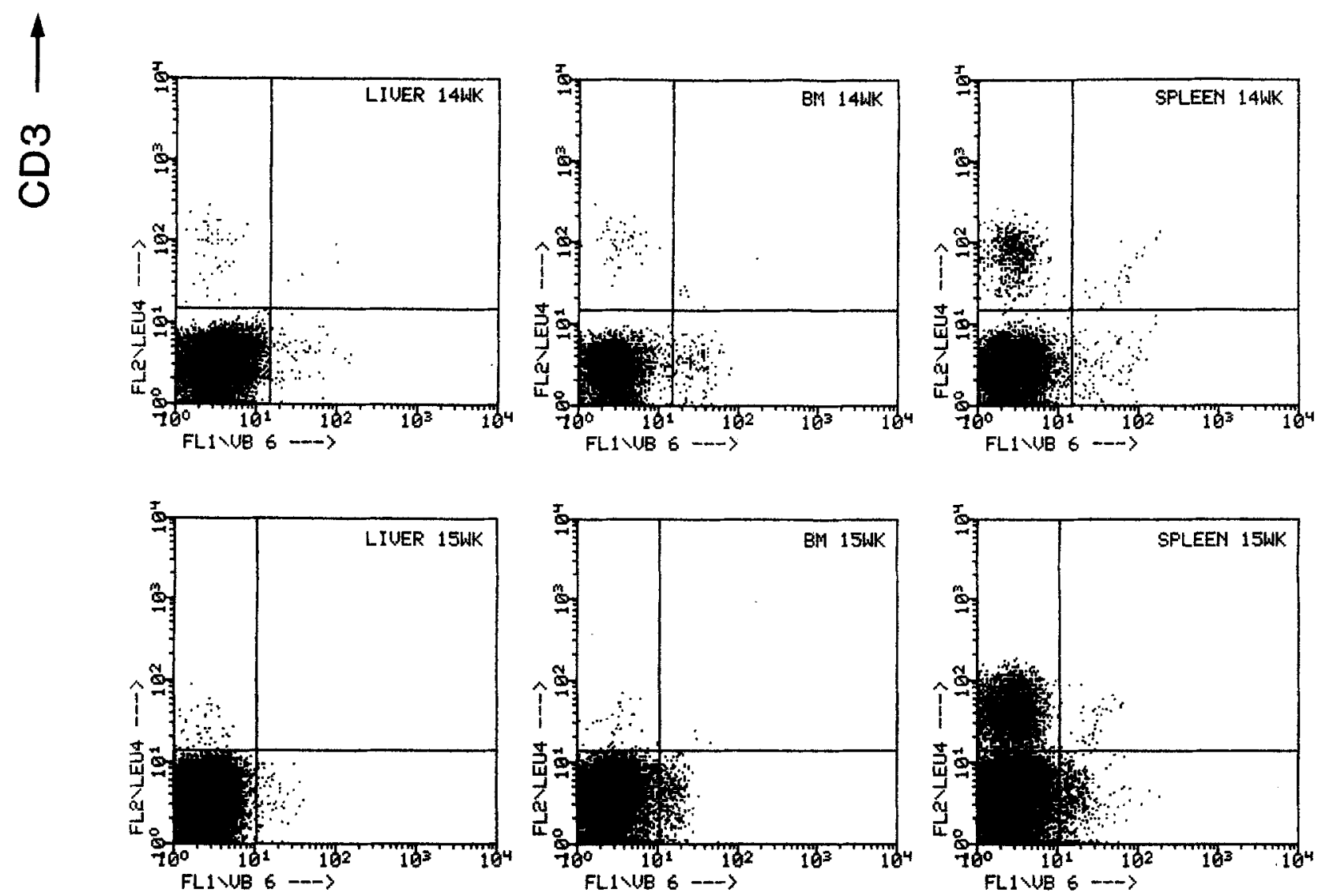

\section{V-beta $6 \longrightarrow$}

Fig. 1. FACS profiles of the detection of CD3(Leu4)+V $66+\mathrm{T}$ cells stained by an FITC-labeled TCRBV6-specific mAb in fetal liver, bone marrow (BM), and spleen obtained at 14 and 15 weeks (Fetus 2) of gestation.

Germany) in the presence of $50 \mathrm{mM} \mathrm{KCl}, 10 \mathrm{mM}$ Tris- $\mathrm{HCl}$ (pH 8.4), $4 \mathrm{mM} \mathrm{MgCl} 2,0.5 \mathrm{mM}$ of each dNTP, and $0.06 \mathrm{mg} / \mathrm{ml}$ BSA in a final volume of $100 \mu 1$. PCR cycles consisted of $1 \mathrm{~min}$ denaturation at $97^{\circ} \mathrm{C}, 1 \mathrm{~min}$ annealing at $54^{\circ} \mathrm{C}$, and $1 \mathrm{~min}$ extension at $74^{\circ} \mathrm{C}$ in a Bio-Med Thermocycler 60 . As the amount of $T C R$ message within an organ (liver, bone marrow, gut, and cord blood as opposed to thymus and spleen) varied greatly, an internal control reaction for the total amount of TCR product detected in each cDNA preparation was included in the experiments. To this end, a PCR reaction was performed, using the $3^{\prime}$ antisense TCR $C$ primer mentioned above and a sense primer specific for the $5^{\prime}$ region of the constant gene element. PCR reactions were also performed without template CDNA as a negative control. In order to assess the efficiency of the TCRAV and TCRBV primers, adult PBMC were included in all experiments. The analysis of the $T C R A V$ and $T C R B V$ repertoires was repeated at least three times for each organ. The possibility of maternal peripheral blood contamination was excluded by the lack of detection of $\mathrm{IgG}$-encoding transcripts in RNA obtained from the fetal organs (Raaphorst et al. 1992).

In order to maximize the chance of detecting TCR rearrangements that might be present at trace levels, the PCR reactions were performed for up to 40 cycles. The sequences of the primers have been described (Choi et al. 1989; Oksenberg et al. 1990; Lambert et al. 1992; Hawes et al. 1993; Struyk et al. 1993).
Ten $\mu$ l of the PCR reactions and serial dilutions (undiluted 5 times, and 25 times diluted) of the internal control amplifications were fractionated on a $1 \%$ agarose gel in $0.5 \times$ tris-borate, blotted onto nylon membranes (Biotrace HP; Gelman Sciences, Ann Arbor, MI), and screened with ${ }^{32} \mathrm{P}-$ labeled probes specific for the $T C R A C$ or $T C R B C$ region, according to protocols supplied by the manufacturer of the membranes. Autoradiography was performed using Kodak XAR films (Rochester, NY).

\section{Results}

FACS analysis of TCR $V$ gene expression in fetal liver, bone marrow, and spleen. In Table 1 the results of the FACS analysis of TCR $V$ gene usage by human fetal T cells, obtained at $14(n=1)$ and 15 weeks $(n=2$; fetus 1 and 2) of gestation, are shown. A representative example of the FACS profiles obtained for detection of $T C R V$ gene expression within various fetal tissues is presented in Figure 1. $\mathrm{CD}^{+} \mathrm{T}$ cells expressing the various TCRAV and TCRBV gene elements were de- 
tectable in all fetal tissues analyzed but were, in contrast to spleen, present at extremely low numbers in liver and bone marrow. For instance, in the liver and bone marrow of 14- and 15-week-old fetuses, approximately $0.35 \%$ to $2.5 \%$ of the gated nucleated cells were $\mathrm{CD}^{+}$ (data not shown). Most TCRAV and TCRBV gene families tested for were expressed in these fetal organs, albeit at different levels. As shown in Table 1, the degree of expression of these TCRAV and TCRBV gene families appeared to be subject to individual differences. This is exemplified by the expression level of the

Table 1. FACS analysis of membrane-expressed TCR $V$ elements.

\begin{tabular}{|c|c|c|c|c|}
\hline & $\mathrm{V}$ chain & 14-wk fetus & $\begin{array}{l}15 \text {-wk fetus } \\
\text { (1) }\end{array}$ & $\begin{array}{l}15 \text {-wk fetus } \\
\text { (2) }\end{array}$ \\
\hline \multirow[t]{13}{*}{$\underline{\mathrm{L}}$} & $v \beta 2$ & 5.3 & 7.5 & 1.9 \\
\hline & Vß3 & 4.5 & 4.3 & 1.8 \\
\hline & $\mathrm{T} \beta 5 \mathrm{a}$ & 4.3 & 2.8 & 2.0 \\
\hline & $V \beta 5 \mathrm{~b}$ & 4.6 & 2.7 & 0.8 \\
\hline & $V \beta 5 c$ & 6.7 & 5.3 & 2.7 \\
\hline & $v \beta 6$ & 5.0 & 1.8 & 2.1 \\
\hline & $v \beta 8$ & 7.0 & - & 2.7 \\
\hline & $V \beta 8 \mathrm{~b}$ & 5.5 & - & 2.0 \\
\hline & $V \beta 12$ & 7.6 & 2.5 & 2.7 \\
\hline & Vß17 & 0.7 & - & 0.4 \\
\hline & $V \beta 19$ & 6.5 & 4.8 & 1.5 \\
\hline & $V \propto 2$ & 2.5 & 6.1 & 1.8 \\
\hline & $V \alpha 12$ & 4.1 & - & 1.4 \\
\hline \multirow[t]{13}{*}{$\underline{\mathrm{BM}}$} & $v \beta 2$ & 10.9 & 8.0 & 7.7 \\
\hline & VB3 & 0.0 & 4.0 & 7.4 \\
\hline & $v \beta 5 a$ & 2.0 & - & 2.0 \\
\hline & $V \beta 5 b$ & 0.7 & 4.0 & 5.7 \\
\hline & $V \beta 5 \mathrm{c}$ & 1.8 & 8.6 & 5.0 \\
\hline & $v \beta 6$ & 4.2 & 4.3 & 4.0 \\
\hline & $V \beta 8$ & 7.9 & - & 4.8 \\
\hline & $V \beta 8 b$ & 4.5 & - & 5.5 \\
\hline & $v \beta 12$ & 5.4 & - & 6.2 \\
\hline & $\mathrm{V} \beta 17$ & 0.0 & - & 5.2 \\
\hline & Vß19 & 7.2 & - & 7.4 \\
\hline & $V \alpha 2$ & 0.8 & - & 2.9 \\
\hline & $V \alpha 12$ & 3.3 & - & 5.0 \\
\hline \multirow[t]{13}{*}{$\underline{S}$} & $v \beta 2$ & 4.2 & 5.7 & 10.2 \\
\hline & $V \beta 3$ & 9.2 & 3.6 & 1.1 \\
\hline & $\mathrm{V} \beta 5 \mathrm{a}$ & 3.1 & - & 2.6 \\
\hline & $V \beta 5 b$ & 2.6 & 0.8 & 0.9 \\
\hline & $V \beta 5 \mathrm{c}$ & 6.7 & - & 3.5 \\
\hline & $v \beta 6$ & 2.5 & - & 1.3 \\
\hline & V $\beta 8$ & 7.5 & - & 3.4 \\
\hline & $\mathrm{V} \beta 8 \mathrm{~b}$ & 3.2 & - & 2.3 \\
\hline & $V \beta 12$ & 5.2 & - & 4.6 \\
\hline & $V \beta 17$ & 0.0 & - & 0.3 \\
\hline & VB19 & 3.4 & - & 2.8 \\
\hline & $\mathrm{V} \alpha 2$ & 2.8 & - & 1.8 \\
\hline & Vo12 & 4.0 & - & 1.8 \\
\hline
\end{tabular}

FACS analysis of membrane-expressed TCR $V$ elements by $\mathrm{CD}^{+}$ $T$ cells isolated from liver (L), bone marrow (BM), and spleen (S) of a 14-week-old human fetus and two 15-week-old fetuses (Fetus 1 and Fetus 2). Values are expressed as the percentage of $\mathrm{CD}^{+}$ $\mathrm{T}$ cells expressing the indicated $\mathrm{V}$ chain; $-\mathbf{=}$ not done.

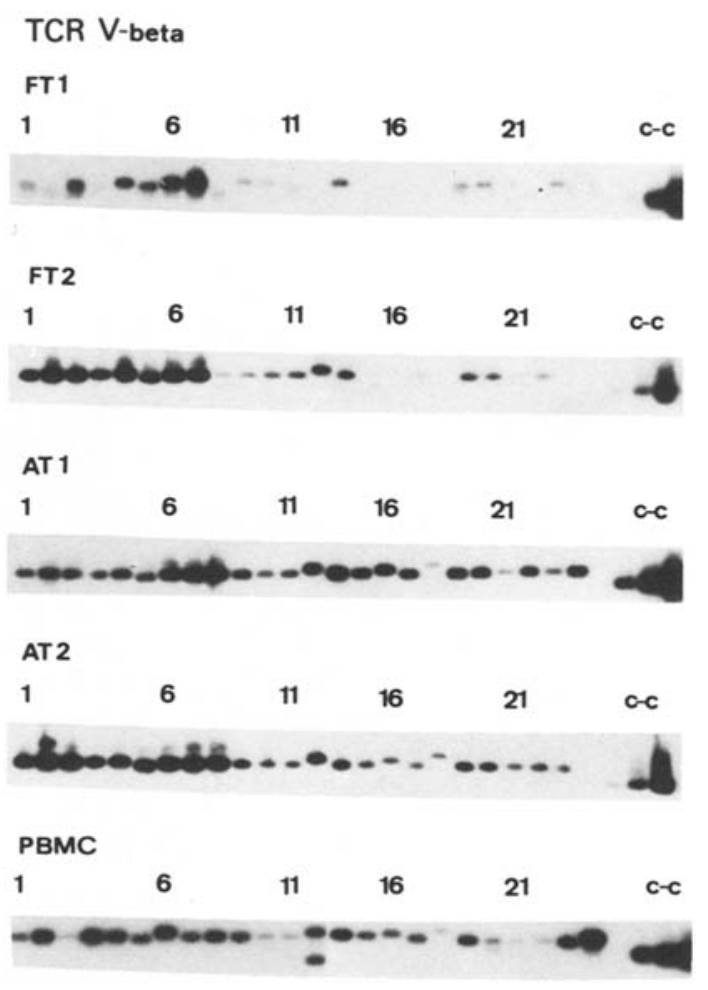

Fig. 2. TCRBV gene family repertoire analyzed by PCR in two human fetal thymi (17 weeks of gestation; FT1 and FT2), two postpartum thymi (AT1 and AT2), and adult PBMC (all 26 cycles). C-C is the serially diluted control amplification of the constant locus of the TCR. Note: TCRBV5 rearrangements were detected in two separate PCR reactions, using two different primers (TCRBV5a and TCRBVSb).

TCRVB2 element, which differed when the liver and spleen obtained from two age-matched fetuses (fetus 1 and 2) were compared. Variable patterns of TCR $V$-gene usage could be discerned for other $V$ elements analyzed as well.

PCR analysis of TCR $V$ gene expression in thymi. To expand our studies with mAbs, we subsequently determined the expression of TCRBV and TCRAV elements by PCR. In Figures 2 and 3 the Southern analyses of the expression of TCRBV and TCRAV families in two human fetal thymi at 17 weeks of gestation (FT1 and FT2) and two post-partum thymi (AT1 and AT2) in comparison to adult PBMC are shown. The majority of the $T C R B V$ and the TCRAV families were detectable in the post-partum thymi and adult PBMC. The expression level of $T C R B V$ and TCRAV families in the fetal thymi was subject to more variation: although the frequency of usage of the majority of the multi-member families (TCRBV1-TCRBV8 and TCRBV10-TCRBV13) was comparable in FT1, FT2, AT1, and AT2, the majority of the single-member families (for instance the TCRBV15-TCRBV18 and the recently identified 


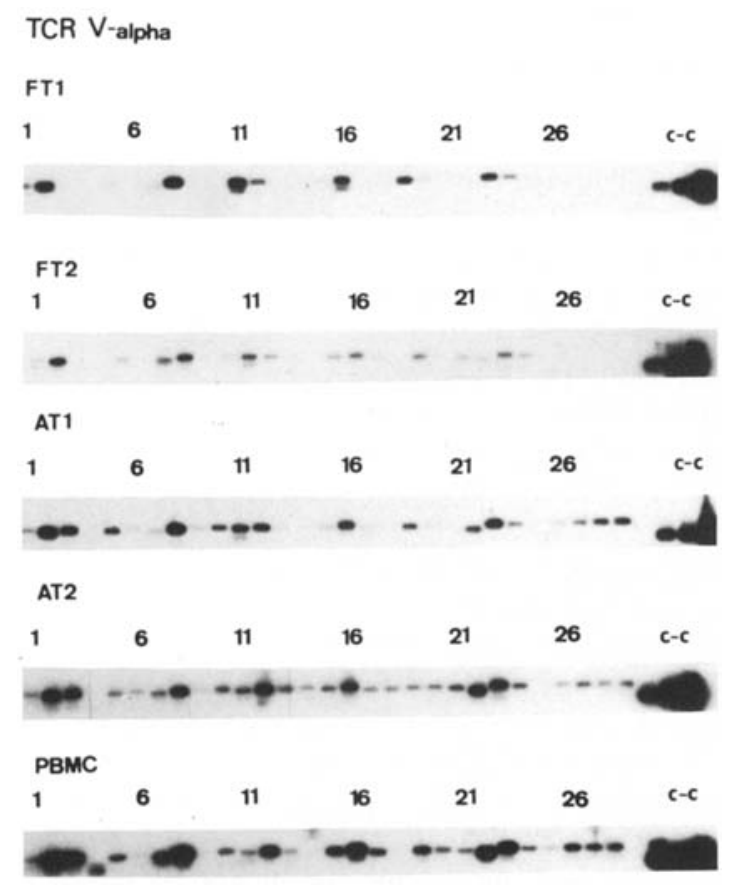

Fig. 3. TCRAV repertoire analyzed by PCR following 30 cycles in two human fetal thymi (17 weeks of gestation; FT1 and FT2), two post-partum thymi (AT1 and AT2), and adult PBMC.

TCRAV24-TCRAV29 gene families) appeared to be expressed at a lower level in both fetal thymi.

PCR analysis of TCR $V$ gene expression in fetal liver, bone marrow, spleen, gut, and cord blood. Determination of the TCRBV repertoire in the 13-week-old fetus showed that almost all of the TCRBV families were detectable in cord blood, gut, and spleen, whereas $T C R B V$ gene usage appeared to be restricted in liver and bone marrow (Fig. 4). Similarly, most of the TCRAV families tested for were readily detectable in the peripheral organs of the 13-week-old fetus with the exception of the TCRAV24-TCRAV29 single-member gene families (Fig. 5). As found in the analysis of TCRBV gene families, the level of expression of the various TCRAV gene families differed markedly in 13-week-old fetal liver and bone marrow compared to the expression of these TCRAV gene families in the periphery. In the 11-week-old fetus, the TCRBV gene family usage profiles exhibited a restricted pattern in both hematopoietic and peripheral organs which was most likely related to the low percentage of $\mathrm{CD} 3+\mathrm{T}$ cells in fetal organs at this gestational age. In addition, TCRAV rearrangements were barely detectable in the investigated organs of this fetus (data not shown).

\section{TCR V-beta}
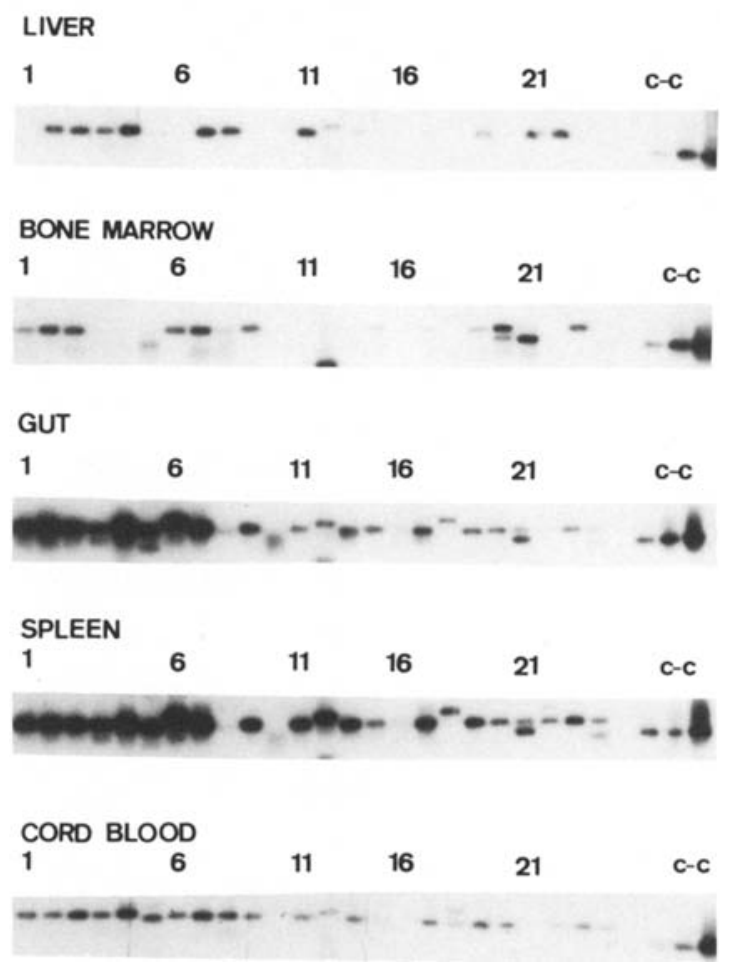

Fig. 4. TCRBV repertoire analyzed by PCR in human fetal liver (35 cycles), bone marrow ( 35 cycles), gut (30 cycles), spleen (30 cycles), and cord blood ( 35 cycles) obtained from a human fetus at 13 weeks of gestation. Note: TCRBV5 rearrangements were detected in two separate PCR reactions, using two different primers (TCRBV5a and TCRBV5b).

\section{Discussion}

PCR analysis of the usage patterns of TCRAV and $T C R B V$ families by $\mathrm{T}$ cells in adult PBMC and postpartum thymi indicated that all families identified to date were detectable in these tissues. In the oldest fetal samples analyzed, the 17-week-old thymi, the majority of the TCR $V$ gene families were detectable as well, although some families appeared to be underrepresented in comparison to post-partum thymi and adult peripheral blood. This was most clearly illustrated by considering the single-member TCRAV and TCRBV gene families. The employment of the various TCRAV and TCRBV families as detected by PCR in the 13-week-old peripheral fetal tissues (gut, spleen, and cord blood) was extensive, and more diverse than the repertoire of the $\mathrm{T}$ cells in the corresponding primary hematopoietic organs (liver and bone marrow).

In analogy with mouse fetal T-cell development (Roth et al. 1991) and human fetal B-cell development (Schroeder and Wang 1990; Raaphorst et al. 1992), the apparent restrictions in human TCRAV and TCRBV family expression could reflect actual preferential usage of TCR $V$ gene elements in T-cell precursors derived 


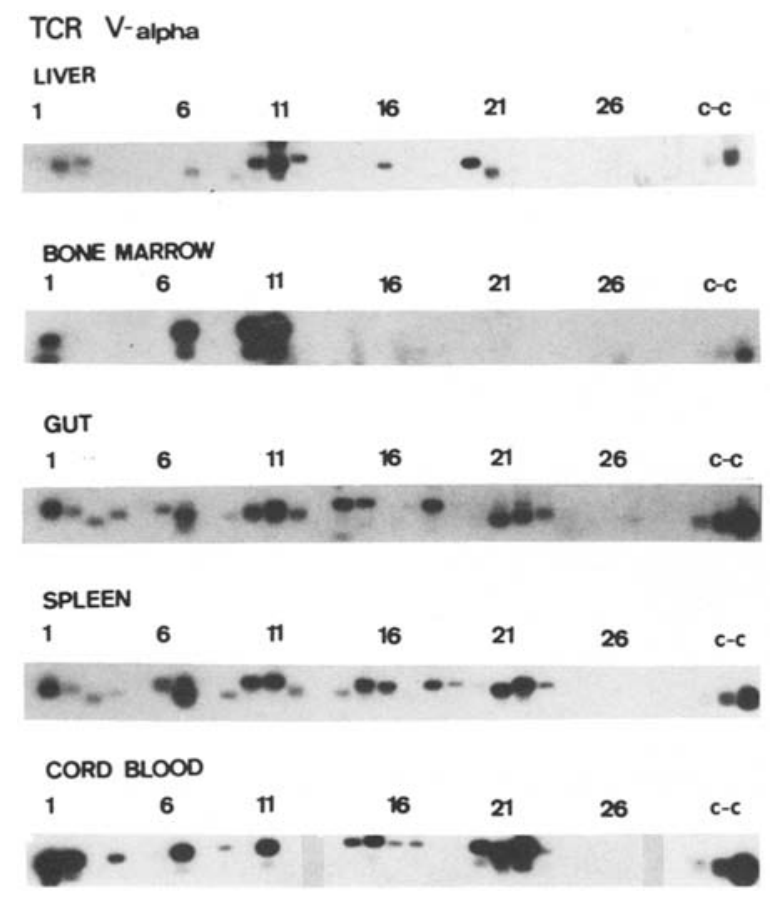

Fig. 5. TCRAV repertoire analyzed by PCR in human fetal liver (37 cycles), bone marrow ( 38 cycles), gut ( 35 cycles), spleen (35 cycles), and cord blood ( 35 cycles) obtained from the same fetus at 13 weeks of gestation.

from liver and bone marrow at early fetal ages. However, considering the more diverse $T C R$ repertoire in the periphery of these fetuses, the low number of immature and mature $\mathrm{CD}^{+}+\mathrm{T}$ cells, especially in the hematopoietic tissues, probably lies at the heart of the apparent restricted phenotype of TCR $V$ family usage. This was reflected by the number of cycles of PCR required to obtain a comparable level of detection in the various tissues (Figs. 2-5). Also, FACS analysis of the expression of TCRAV and TCRBV gene products of $\mathrm{CD}^{+}$ T-cells in 14- and 15-week-old fetal liver, bone marrow, and spleen (Fig. 1; Table 1) indicated that the majority of the TCR $V$ regions tested for were detectable, although sometimes at an extremely low level. The percentage of staining of $\mathrm{CD}^{+} \mathrm{T}$ cells in fetal tissue for each individual $\mathrm{mAb}$ was in a range similar to the staining patterns in PBMC, as previously reported by our group (Lambert et al. 1992; Hawes et al. 1993). The $\mathrm{mAb}$ staining profiles suggested that the patterns of expression of TCR $V$ families were subject to individualspecific variation, which has recently also been described in several other studies of TCR $V$ gene expression in unrelated individuals (Akolkar et al. 1992; Robinson 1992; Rosenberg et al. 1992; Hawes et al. 1993) and T-cell subsets (Davey et al. 1991; Grunewald et al.
1992). It is of note that $T C R V$ gene family-specific PCR reactions were designed to detect all known members of a given family. Consequently, this may also explain why the FACS and PCR analyses were not completely overlapping, because the mAbs used are specific for a single member only.

As the peripheral fetal TCR $V$ gene repertoire was extensive both in PCR and FACS analysis, our data show that in early human fetal TCR rearrangements $V$ elements belonging to the majority of $T C R V$ gene families are used by fetal $\mathrm{T}$ cells. Recently reported data obtained by other groups support this conclusion: studies of TCRBV expression in human fetal thymus and spleen at 15-22 weeks of gestation also demonstrated that all of the 20 tested TCRBV gene families can be used in TCR rearrangements at this stage of fetal development (Doherty et al. 1991; Bonati et al. 1992). In addition, transplantation of 18- to 20-week-old human fetal thymus and liver in SCID-hu mice demonstrated that all investigated TCRBV elements were expressed by the repopulating T cells (VandeKerckhove et al. 1992). Furthermore, the relative expression levels of TCRBV elements expressed by $\mathrm{T}$ cells in the SCID-hu fetal thymus differed in comparison to the TCRBV usage patterns of $T$ cells in human post-partum thymi (Doherty et al. 1991; VandeKerckhove et al. 1992), which is compatible with our results.

Taken together, our data indicate that there are no apparent major limitations in the usage of TCRAV and $T C R B V$ gene families in the fetal and adult tissues analyzed.

Acknowledgments. We thank Dr. R. R. P. de Vries, Dr. C. J. M. Melief, Dr. J. Henwood, and Dr. J. Teale for critically reading the manuscript, J. L. M. Waaijer for her assistance in the FACS analyses, H. Tanke for fruitful discussions, and H. J. van der Bijl for creating a stimulating environment.

\section{References}

Abe, J. Immunocytochemical characterization of lymphocyte development in human embryonic and fetal livers. Clin Immunol Immunopathol 51: 13-21, 1989

Akolkar, P. N., Gulwani-Akolkar, B., Pergolizzi, R., Bigler, R. D., and Silver, J. Influence of HLA genes on T cell receptor V segment frequencies and expression levels in peripheral blood lymphocytes. J Immunol 150: 2761-2773, 1992

Asma, G. E. M., Langlois van den Bergh, R., and Vossen, J. M. Use of monoclonal antibodies in a study of the development of $\mathrm{T}$ lymphocytes in the human fetus. Clin Exp Immunol 53: $429-436,1983$

Asma, G. E. M., Langlois van den Bergh, R., and Vossen, J. M. Development of pre-B and B-lymphocytes in the human fetus. Clin Exp Immunol 56: 407-414, 1984

Bonati, A., Zanelli, P., Ferrari, S., Plebani, A., Starcich, B., Savi, M., and Neri, T. M. T-cell receptor $\beta$ chain gene rearrangement and expression during human tyhmic ontogenesis. Blood 79 : $1472-1483,1992$ 
Born, W., Yagüe, J., Palmer, E., Kappler, J., and Marrack, P. Rearrangement of $T$ cell receptor $\beta$ chain genes during T-cell development. Proc Natl Acad Sci USA 82: 2925-2929, 1985

Brenner, M. B., McLean, J., Dialynas, D. P., Strominger, J. L., Smith, J. A., Owen, F. L., Seidman, J. G., Ip, S., Rosen, S., and Krangel, M. S. Identification of a putative second $\mathrm{T}$ cell receptor. Nature 322: 145-149, 1986

Brenner, M. B., McLean, J., Scheft, H., Warnke, R. A., Jores, N., and Strominger, J. L. Characterization and expression of human $\alpha / \beta \mathrm{T}$ cell receptor by using a framework monoclonal antibody. J Immunol 138: 1502-1509, 1987

Campana, D., Janossy, G., Coustan-Smith, E., Amlot, P. L., Tian, W.-T., Ip, S., and Wong, L. The expression of T cell receptorassociated proteins during $\mathrm{T}$ cell ontogeny in man. $J$ Immunol 142: $57-66,1989$

Choi, Y., Kotzin, B., Herron, L., Callahan, J., Marrack, P., and Kappler, J. Interaction of Staphylococcus aureus toxin "superantigens" with human T-cells. Proc Natl Acad Sci USA 86: $8941-8945,1989$

Concannon, P., Pickering, L. A., Kung, P., and Hood, L. Diversity and structure of human T cell receptor $\beta$ chain variable genes. Proc Natl Acad Sci USA 83: 6598-6602, 1986

Davey, M. P., Meyer, M. M., Munkirs, D. D., Babcock, D., Braun, M. P., Hayden, J. B., and Bakke, A. C. T-cell receptor variable region $\beta$ chain genes show differential expression in CD4 and CD8 cells. Hum Immunol 32: 194-202, 1991

Doherty, P. J., Roifman, C. M., Pan, S., Cymerman, U., Ho, S. K. W., Thompson, E., Kamel-Reid, S., and Cohen, A. Expression of the human $\mathrm{T}$ cell receptor V $\beta$ repertoire. $\mathrm{Mol} \mathrm{Im}$ munol 28: 607-612, 1991

Elliot, J. F., Rock, E. P., Patten, P. A., Davis, M. M., and Chien, Y. $H$. The adult $\mathrm{T}$ cell receptor delta-chain is diverse and distinct from that of fetal thymocytes. Nature 331: 627-631, 1988

Ferradini, L., Roman-Roman, S., Azocar, J., Michalaki, H., Triebel, F., and Hercend, T. Studies on the human T cell receptor $\alpha /$ $\beta$ variable region genes. II. Identification of four additional V $\beta$ subfamilies. Eur J Immunol 21: 935-942, 1991

Furley, A. J., Mitzutani, S., Weilbaecher, K., Dhaliwal, H. S., Ford, A. M., Chan, L. C., Molgaard, H. V., Toyonaga, B., Mak, T. W., Elsen, P. J. van den, Gold, D., Terhorst, C., and Greaves, M. F. Developmentally regulated rearrangement and expression of genes encoding the T-cell receptor-T3 complex. Cell 46: $75-87,1986$

Gale, R. P. Development of the immune system in human fetal liver. Thymus 10: 45-56, 1987

Grunewald, J., Jeddi-Tehrani, M., Pisa, E., Janson, C. H., Andersson, R., and Wigzell, $\mathrm{H}$. Analysis of J $\beta$ gene segment usage by $\mathrm{CD} 4+$ and $\mathrm{CD} 8+$ human peripheral blood $\mathrm{T}$ lymphocytes. Int Immunol 4: 643-650, 1992

Hawes, G. E., Struyk, L., and Elsen, P. J. van den. Differential usage of T-cell receptor V-gene segments in $\mathrm{CD} 4^{+}$and $\mathrm{CD} 8^{+}$ subsets of $\mathrm{T}$ lymphocytes in monozygotic twins. $J$ Immunol 150: $2033-2045,1993$

Haynes, B. F., Singer, K. H., Denning, S. M., and Martin, M. E. Analysis of expression of $\mathrm{CD} 2, \mathrm{CD} 3$ and $\mathrm{T}$ cell antigen receptor molecules during early human fetal thymic development. J Immunol 141: 3776-3784, 1988

Ito, K., Bonneville, M., Takagaki, Y., and Tonegawa, S. Diffrent $\gamma \delta$ receptors are expressed on thymocytes at different stages of development. Proc Natl Acad Sci USA 86: 631-635, 1989

Kimura, N., Toyonaga, B., Yoshikai, Y., Triebel, F., Debre, P., Minden, P. D., and Mak, T. W. Sequences and repertoire of human T cell receptor $\alpha$ and $\beta$ chain variable region genes in thymocytes. Eur J Immunol 17: 375-383, 1987
Krangel, M. S., Yssel, H., Brocklehurst, C., and Spits, H. A distinct wave of human $\mathrm{T}$ cell receptor $\gamma \delta$ lymphocytes in the early fetal thymus: evidence for controlled gene rearrangement and cytokine production. $J$ Exp Med 172: 847-859, 1990

Lafaille, J. J., DeCloux, A., Bonneville, M., Takagaki, Y., and Tonegawa, S. Junctional sequences of T cell receptor $\gamma \delta$ genes: implications for $\gamma \delta$ cell lineages and for a novel intermediate of V-(D)-J joining. Cell 59: 859-870, 1989

Lambert, M., Eggermond, M. van, Mascart, F, DuPont, E., and Elsen, P. J. van den. TCR $V \alpha$ - and $V \beta$-gene segment use in T-cell subcultures derived from a type III bare lymphocyte syndrome patient deficient in MHC class II expression. Dev Immunol 2: 227-236, 1992

Moore, K. L. The Developing Human. Clinically Oriented Embryology, 4th edn., W. B. Saunders Company, Philadelphia, 1988

Oksenberg, J. R., Stuart, S., Begovich, A. B., Bell, R., Erlich, H. A., Steinman, L., and Bernard, C. C. A. Limited heterogeneity of rearranged T-cell receptor $\mathrm{V} \alpha$ transcripts in brains of multiple sclerosis patients. Nature 345: 344-346, 1990

Plaza, A, Kono, D. H., and Theofilopoulos, A. N. New human V $\beta$ genes and polymorphic variants. $J$ Immunol 147 : $4360-4365,1991$

Raaphorst, F. M., Timmers, E., Kenter, M., Tol, M. J. D. van, Vossen, J. M., and Schuurman, R. K. B. Preferential utilization of germ-line $\mathrm{V}_{\mathrm{H}} 3$ elements and short diverse third complementarity determining (CDR3) regions in human fetal B lymphocyte immunoglobulin heavy chain rearrangements. Eur J Immunol 22: 247-251, 1992

Robinson, M. A. The human T cell receptor $\beta$-chain complex contains at least 57 variable gene segments. $J$ Immunol 146 : 4392-4397, 1991

Robinson, M. A. Usage of human T cell receptor $V \beta, J \beta, C \beta$ and $V \alpha$ gene segments is not proportional to gene number. Hum Immunol 35: 60-67, 1992

Roman-Roman, S., Ferradini, L., Azocar, J., Genevee, C., Hercend, T., and Triebel, F. Studies on the human T cell receptor $\alpha / \beta$ variable region genes. I. Identification of seven additional $\mathrm{V} \alpha$ subfamilies and $14 \mathrm{~J} \alpha$ gene segments. Eur I Immunol 21: 927-933, 1991

Rosenberg, W. M. C., Moss, P. A. H., and Bell, J. I. Variation in human T-cell receptor $\mathrm{V} \beta$ and $J \beta$ repertoire: analysis using anchor polymerase chain reaction. Eur I Immunol 22: $541-549,1992$

Roth, M. E., Holman, P. O., and Kranz, D. M. Non-random use of $\mathrm{J} \alpha$ gene segments. Influence of $\mathrm{V} \alpha$ and $\mathrm{J} \alpha$ localization. $J \mathrm{Im}$ munol 147: 1075-1081, 1991

Sambrook, J., Fritsch, E. F., and Maniatis, T. Molecular Cloning. A Laboratory Manual, 3rd edn. Cold Spring Harbor Laboratory, Cold Spring Harbor, 1989

Samelson, L. E., Lindsten, T., Fowlkes, B. J., Elsen, P. J. van den, Terhorst, C., Davis, M. M., Germain, R. N., and Schwartz, R. H. Expression of genes of the $\mathrm{T}$ cell antigen receptor complex in precursor thymocytes. Nature 315: 765-768, 1985

Sánchez, M. J., Gutiérrez-Ramos, J. C., Fernández, E., Leonardo, E., Lozano, J., Martínez-A, C., and Toribio, M. L. Putative pre-thymic T cell precursors within the early human embryonic liver: a molecular and functional analysis. $J$ Exp Med 177: $19-33,1993$

Schatz, D. G., Oettinger, M. A., and Schlissel, M. S. V(D)I recombination: molecular biology and regulation. Annu Rev Immunol 10: 359-383, 1992

Schroeder, H. W., Jr., and Wang, J. Y. Preferential utilization of conserved immunoglobulin heavy chain variable gene segments during human fetal life. Proc Natl Acad Sci USA 87 : $6146-6150,1990$ 
Strominger, J. L. Developmental biology of T cell receptors. Science 244: 943-950, 1989

Struyk, L., Kurnick, J. T., Hawes, G. E., Laar, J. M. van, Schipper, R., Oksenberg, J. R., Steinman, L., Vries, R. R. P. de, Breedveld, F., and Elsen, P. J. van den. TCR V-gene usage in synovial fluid lymphocytes of patients with chronic arthritis. Hum Immunol 37: 237-251, 1994

VandeKerckhove, B. A. E., Baccala, R., Jones, D., Kono, D. H., Theofilopoulos, A. N., and Roncarolo, M.-G. Thymic selection of human $\mathrm{T}$ cell receptor $\mathrm{V} \beta$ repertoire in SCID-hu mice. $J$ Exp Med 176: 1619-1624, 1992

Van der Stoep, N., Krijger, R. de, Bruining, J., Koning, F., and Elsen, P. J., van den. Analysis of early fetal T-cell receptor $\delta$ chain in humans. Immunogenetics $32: 331-336,1990$
Van Dongen, J. J. M., Quertermous, T., Bartram, C. R., Gold, D. P., Wolvers-Tetteroo, I. L. M., Comans-Bitter, W. M., Hooijkaas, H., Adriaansen, H. J., Klein, A. de, Raghavachar, A., Ganser, A., Duby, A. D., Seidman, J. G., Elsen, P. J. van den, and Terhorst, C. T-cell receptor-CD3 complex during early $\mathrm{T}$ cell differentiation: analysis of immature $T$ cell acute lymphoblastic leukemias (T-ALL) at DNA, RNA and cell membrane level. J Immunol 138: 1260-1269, 1987

Van Eggermond, M. C. J. A., Rijkers, G. T., Kuis, W., Zegers, B. J. M., and Elsen, P. J. van den. T cell development in a major histocompatibility complex class II deficient patient. Eur $J$ Immunol 23: 2585-2591, 1993

Wilson, R. K., Lai, E., Concannon, P., Barth, R. K. and Hood, L. E. Structure, organization and polymorphism of murine and human T-cell receptor alpha and beta chain families. Immunol Rev 101: $149-172,1988$ 